THE comet was well seen nere on Monday, October 23, for some considerable time about 5 a.m., though clouds occasionally hid part of it. I noticed the following:-1. The length that was clearly visible was such, that if the head had been placed on Sirius, the tail would have reached to Orion's belt. 2. The lower edge of the tail was comparatively sharp and bri,htly defined, while there was ro well-defined upper edge. 3. At first sight the tail ended, fairly abraptly, in a short fork. "But on glancing to one side, so as to allow the image to fall on a more sensitive part of the retina, one became aware that these two forks were continued in a very faint and hazy manner as far again as the length of the comet first noticed (mentioned and measured in (I.)) Or, more strictly, one became aware of a black rift in the sky behind the comet, in its direction, above and below which the sky was faintly luminous. One may say that at first sight the comet ended like a house-martin's, on more careful observation like a swallow's, tail. The total lengrh of the comet thus seen was enormous; and the appearance suggested an even greater extension.

Cheltenham, October 24

Although the fact is mentioned in NATURE of the 5 th inst., that the comet was observed by Mr. Finlay, the Fir.t Assistant to the Astronomer-Royal at the Cape of Good Hope, at $5 \mathrm{a} . \mathrm{m}$. on September $\delta$, perhaps the $t$ llowing graphic account of its appearance, which I extract from a letter received this morning from my friend Mr. G. B. Bennett, dated Water-Hof, Cape Town, September 26, may have some interest. $\mathrm{Mr}$. Bennett believed bimself the earliest observer, but he does not consider the comet more conspizuous on this occasion than it was in 1843

"I take an especial intere $t$ in our present visitor, as I fancy that I am the very first person who saw it, and this was on the 8 th inst. at 5 a.m. I was attracter into the garden by the marvellous brilliancy of the stars. On turning my eyes ea-tward I detected a stranger at once; it did not appear as a comet, but I knew that there ought not to be any large star in the spot occupied. It was about midway between Alpherat (Cor Hydræ) and Regulus; the latter, however, was not visible at the time I called to my daughter, and asked her to put ber head out of the window, and she at once said, 'a comet.' I then wrote a nute to the Editor of the Cape Times announcing it; this letter did not reach him, it would be long to explain why. . . . It is of such size and brilliancy as to be seen in the brightest sunshine. I saw it September 18 between noon and I p.m. Dr. Gill is reported to have said, 'the largest for 2 co years.' I don't believe he said so; if so, he could not have seen the one of March, I843."

My friend adds that he has ascertained most po itively that it was not observed from the deck of either of the mail steamers Athenian or Garth Castle, then approaching the Cape. The latter carried Father Perry and the members of the Transit of Venus Expedition. "My belief is that it came within the ken of buman vision on the morning of the 8th September, and not before." His station of observation, Waterhof, is about half-way up Table Mountain.

October 19

J. H. LEFROY

REFERRING to my letter of the $16 \mathrm{th}, \mathrm{I}$ beg to say that the R.A. of the "neighbouring object" should have been Ioh. IIm., and that it was probably, not Schmidt's comet, as suppcsed, but the 7 th or 8th mag. star I9980 Lalande, which does not appear in the B.A. Catalogue, or in the V.S. Catalogue, or in the large maps of the S.D.V.K., or on Mattly's Globe. It appeared to me of much greater magnitude than the above.

Bray, Co. Wicklow, Cctober 2t Wentworth ERck

THE magnificent comet now visible in our eastern sky shortly before sunrise is no dout being observed in England. In case it should not I may add that its approximate position at $4 \mathrm{~h} .5 \mathrm{om}$. a.m. (local mean time) this morning as determined by my equatorially mounted ( $4 \frac{1}{4}$ inch Cooke) tele: cope was R.A. Ioh. $55 \mathrm{~m}$., South declination $3^{\circ} 29^{\prime}$. The tail by estimation is about $14^{\circ}$, and of unusual breadth. The borders of the tail appear much brighter than the central part.

Lahore, The Punjab, India, September 25

\section{The Proposed Bridge over the Forth}

IT is no small evidence of the importance of this great undertaking, that the proposed scheme should have drawn from Sir
George Biddell Airy such severe criticism as that which appeared in last weel's NATURE. Coming from such a source, this criticism is sure, not only to receive the most careful ccnsideration of those few who are sufficiently conversant with such matters to form their own opinion, but is sure to have great weight with the much larger class who accept the opinion of those they conceive best able to judge. It therefore behoves those who are respon. sible for this scheme, to make the best answer they can. Whether they will be alle to remove altogether the impression adverse to the scheme, may well be doubted; but for my own part. I do not anticipate that they will find much difficulty in meeting the objections raiced, in so far as these are definite. It is not my pre ent object to defend, or even to discuss the merits of the proposed bridge; what I wish to point out is that the knowledge of engineers as regards the theory of structures, is not s imperfect, or their methods of designing such guesswork as might be inferred from the tone of the criticism.

Sir Gecrge Biddell Airy expre ses alarm lest in the design due consideration has not been paid to the "theory of buckling;" but whether this is so or not, does not appear from any circumstance to which he has referred.

To make a strut r $r$ "thrust-bar" 340 feet long to : ustain a thrust of several hundred tons, is duubtless a stupendaus un. dertaking, but so is a bridge to carry a railway over 1700 feet. There is, however, no theoretical reason again th the possibility of such structures; that is to say, assuming the same strength and elastic properties of material as are experienced in existing structures, it appears by the application of the principles of mechanics that botb such distributions and such quantities of material are possible as will assure the safety of these structures. Whether or not such distribution and quantities have been secured in the designs for these struts, could orily be judged of after careful consideration of the proposed lateral sections in conjunction with the longitudinal section, and to these no reference whatever is made in the criticisms.

That the experienced engineers who have made themselves responsible for this design can have overlooked such an important consideration as i uckling is very improbable. There is no possible accident to structures which has received more careful consideration than buckling, or of which the laws have been more definitely ascertained.

The very pretty method, given in the appendix to the com. munication under consideration, for obtaining the formula $\mathrm{W}=\mathrm{C} \frac{\pi^{2}}{a^{2}}$ is a well-known application of the theory of elasticity, and is given by Bresse. ${ }^{1}$ But this formula is known only to apply to prismatic bars very thin, compared with their length, and is therefore of little practical $u=e$. The laws of stiffness and strength for struts of a solid section, were first deduced by Eaton Hodgkinson from his own experiments, and have since been extended to struts of any section by Lewis Gordon ard Rankine.

For wrought iron, putting $P$ for the load, $S$ the area of section, $L$ the length, and $r$ the least radius of gyration of the section ahout any line in that section, the units being inches and lbs., the formula is-

$$
\frac{P}{S}=36,000 \div\left(1+\frac{l 2}{36,000 r^{2}}\right) .
$$

From this it will be seen that $L$ must be very large compared with $r$ before this formula assumes the same form as that which Sir George Biddell Airy has obtained.

Such general formulx are not, however, the only or the chief guides in modern construction; sufficient actual $\epsilon$ xperience has been obtained as regards s uch a great variety of forms for the elementary parts of structures as to furnish rules for the proportioning of every class. And although any novelty such as unprecedented size furni hes matter for grave consideration, both as regards proportions and the poscibilities of art, still the theory and data for assuring reasonable safety are available, and engineers must be much behind the day if they neglect these.

Owens College, October $2 \mathrm{I}$

OSBORNE REYNOLDS

I HAVE read Sir George Airy's critici m of the design for the proposed Forth Bridge with interest. So far as engineers are concerned the letter calls for no reply; but as otbers pardonably ignorant of the present state of engincering science may feel the

2 "Cours de Méchanique appliqué," p. 210 ( 1866 . 